\title{
JAIME EYZAGUIRRE Y SU DEFENSA DE LA HISPANIDAD
}

\section{JAIME EYZAGUIRRE AND HIS HISPANITY DEFENSE}

\begin{abstract}
José Díaz NiEva* JDNIEV@YAHOO.ES

\section{RESUMEN}

En el siglo XX destaca en la historiografía chilena el nombre de Jaime Eyzaguirre; y ello por dos razones: una por sobrepasar la fecha de 1891 , pero otra, tal vez la más importante, por romper el cerco positivista y liberal que había primado hasta entonces. Jaime Eyzaguirre va a hacer historia desde el catolicismo militante y la defensa de la hispanidad.
\end{abstract}

Palabras claves: Historiografía, hispanismo, Chile.

\begin{abstract}
The name of Jaime Eyzaguirre stands out in XXth century Chilean historiography for two reasons. First, because he underpasses the date of 1891; secondly, and mainly, because he breaks the positivist and liberal circle prevailing until then. Jaime Eyzaguirre writes History from a militant Catholicism, defending the idea of Hispanidad.
\end{abstract}

Keywords: Historiography, Hispanism, Chile.

\section{INTRODUCCION}

Era un 18 de septiembre de 1968. En la mayoría de las casas de chilenas se preparaban para festejar las Fiestas Patrias. Un día como ése, de 1810 , el cabildo de Santiago de Chile sembraba la semilla que llevaría a aquel finis terrae austral a proclamar la secesión de la España peninsular. Pero en aquella ocasión, en un pequeño fundo, cerca de la población de Laja, se recibía una fatal noticia: un desafortunado accidente automovilístico, ocurrido pocas horas antes, truncaba la vida de Jaime Eyzaguirre Gutiérrez. Con él desaparecía el hombre que había removido los pilares de la historiografía chilena.

Jaime Eyzaguirre había nacido un 21 de diciembre de 1908 en el seno de una familia perteneciente a la aristocracia tradicional'. Formado en un hogar profundamente católico había recibido una sólida formación, primero en el Liceo Alemán y posteriormente en la Pontificia Universidad Católica de Chile, en donde obtendría, en 1931, su Licenciatura en Derecho, luego de haber presentado una memoria bajo el título de Privilegios Diplomáticos. Síntesis histórica y de Legislación comparada. Pero, no sería el ejercicio de la abogacía su verdadera vocación profesional, la cual abandonaría rápidamente. Hay quien recuerda cómo solía jactarse, remitiéndose al pensador tradicionalista español Juan Vázquez de Mella, de "no haber ejercitado la abogacía por amor a la justicia" 2 .

\footnotetext{
* Académico de la Universidad San Pablo CEU, Madrid.

${ }^{1}$ Los Eyzaguirre que llegan a Chile (1747) tienen una ascendencia vizcaína. El primero de ellos fue Domingo Eyzaguirre Escutado, quien ocuparía el cargo de ensayador mayor de la Real Casa de la Moneda. Entre sus hijos se encontraría Agustín Eyzaguirre Arechavala, el alcalde de Santiago de Chile en 1810 y Presidente Provisional de la República entre 1826-1827. El propio Jaime Eyzaguirre dedicaría algunos de sus trabajos a la historia de su familia: El alcalde del año diez. Editorial Andrés Bello, Santiago de Chile, 1968, y "Generaciones y Semblanzas. Los Antepasados de Don Agustín de Eyzaguirre", en Boletín de la Academia Chilena de la Historia, $\mathrm{N}^{\circ} 9$, Santiago de Chile, 1933, pp. 155-276. Jaime Eyzaguirre era la sexta generación de una larga familia entre cuyos miembros hubo congresistas, ministros o destacados sacerdotes. Virgilio Figueroa. 1925-1931. Diccionario Biográfico y Bibliográfico de Chile, Impr. y Litogr. La Ilustración, Santiago de Chile, tomo III, pp. 110-115.

${ }^{2}$ Comentario recogido en Alvaro Góngora, Alexandrine de la Taille y Gonzalo Vial. 2002. Jaime Eyzaguirre en su tiempo, Universidad Finis Terrae, Editorial Zig-Zag, Santiago de Chile, p. 65.
} 
Durante algún tiempo trabajaría en el Ministerio de Relaciones Exteriores, pero tampoco sería la diplomacia por lo que se decantaría. Jaime Eyzaguirre fue, ante todo y sobre todo, un educador y un historiador.

Su carrera como docente comenzaría en 1932, al ingresar en la Universidad Católica, primero como profesor ayudante, luego como titular; haciéndose cargo de las cátedras de Historia del Derecho e Historia Constitucional de Chile. Posteriormente, en 1953, también ingresaría como docente en la Universidad de Chile. A su muerte una amplía escuela de discípulos se quedaba huérfana de maestro.

Pero, más allá de su papel de docente, sería la historia su gran pasión y vocación. Sus investigaciones se centraron, principalmente, en la historia de Chile, aunque también dedicó numerosos trabajos a la historia de América y de España. Entre sus obras podemos destacar en un primer lugar aquellas que tienen un carácter biográfico, tales como Ventura de Pedro de Valdivia (1942), O'Higgins (1946), que obtendría el primer premio en el certamen nacional organizado por la Municipalidad de Santiago, El Conde de la Conquista (1951) o El alcalde del año diez (1968). Sería precisamente una de estas obras, Chile durante el Gobierno de Errázuriz Echaurren 1896-1901 (1957), la que marcaría un hito en la historiografía de su tiempo. Hasta ese momento se consideraba que la historia de Chile no podía sobrepasar el año de 1891; ésa era la fecha en la que se había detenido Francisco Antonio Encina en su magna obra sobre la materia ${ }^{3}$. Se creía que no existía la suficiente perspectiva histórica para superar ese año ${ }^{4}$. Eyzaguirre al rebasar con una obra de peso (más allá de alguno que otro artículo o breve opúsculo) el mítico año de 1891, había dado uno de los primeros pasos que renovarían la historiografía chilena de su tiempos.

La obra de Eyzaguirre no sólo rompía el marco espacial en el que se venía moviendo la historiografía, sino también la cosmovisión historiográfica iniciada por Diego Barros Arana ${ }^{6}$ y Benjamín Vicuña Mackenna ${ }^{7}$. La obra de éstos últimos se había caracterizado por sus ácidas críticas a la conquista y al período colonial. Este punto, más que el anterior, es el que más molestaba a sus detractores. Aquellos que hacían historia desde un exacerbado dogmatismo liberal y desde el positivismo científico (cuando no desde el materialismo histórico ${ }^{8}$ ) no podían tolerar que Eyzaguirre lo hiciera desde su catolicismo militante y su cosmovisión hispánica, pues ambas son las notas características que marcaron su vida, su labor académica y su labor científica en el campo de la historia.

El trágico accidente de aquel 18 de septiembre de 1968 no sólo truncaba la vida de nuestro personaje, sino que también dejaba inconclusa su labor científica, y ello pese a los 347 trabajos que nos ha legado. En efecto, pocos años antes de su fallecimiento había comenzado a trabajar en su Historia de Chile, de la cual tan sólo se publicaría, en 1965, su primer tomo. Algunos de sus discípulos, años más tarde, lograrían, en una edición posterior, ordenar y publicar lo que debería haber sido el segundo volumen de esta obra9 .

\section{DEFENSA DE LA HISPANIDAD EN CHILE}

En una entrevista, publicada en The Hispanical American Review, el también historiador Mario Góngora del Campo, refiriéndose al tema del hispanismo, afirmaba:

La relación chilena con España y el hispanismo en el siglo XX, por ejemplo, provenía de dos fuentes. Una, que era de naturaleza literaria, derivada de la influencia de Menéndez y Pelayo, la generación de 1898, Menéndez Pidal y la generación poética de 1927. La otra, de índole más ideológica, provenía de La Defensa de la Hispanidad de Ramiro de Maeztu y de la Guerra Civil española ${ }^{10}$.

\footnotetext{
${ }^{3}$ Encina Armanet, Francisco Antonio. 1940 - 1952. Historia de Chile, desde la prehistoria hasta 1891, Santiago de Chile (20 vols).

${ }^{4}$ Leopoldo Castedo ampliaría la obra de Encina llevándola hasta 1924; pero para eso habría que esperar a una reedición (en 1982) del Resumen de la Historia de Chile, en el que se incluye un cuarto volumen enteramente de la obra del intelectual español exiliado en Chile y que ampliaba la edición que ambos (Encina y Castedo) habían publicado en 1954.

${ }^{5}$ Bravo Lira, Bernardino. "Jaime Eyzaguirre, historiografía chilena y conciencia nacional en el siglo XX", en Hanisch Espíndola, Walter et al. 1995. Jaime Eyzaguirre. Historia y Pensamiento, Editorial Universitaria - Universidad Alonso Ovalle. Santiago de Chile, p. 91.

${ }^{6}$ Diego Barros Arana (1830-1907). Pedagogo, diplomático e historiador. Sus obras aún tienen especial vigencia hoy en día, principalmente su monumental Historia General de Chile, publicada en 16 volúmenes entre 1884-1902.

${ }^{7}$ Benjamín Vicuña Mackenna (1831-1886). Político e historiador. Su principal obra fue Historia General de la República de Chile. Desde la Independencia a nuestros días, 1866-1872 (5 vols).

${ }^{8}$ Esta tendencia historiográfica tiene como máximos representantes a Hernán Ramírez Necochea (1917-1979) y a Luis Vitale (1927)

${ }^{9}$ Ver Historia de Chile. Génesis de la nacionalidad ( $2^{\mathrm{a}}$ Edición), Zig-Zag, Santiago de Chile, 1973.

${ }^{10}$ Recogido en Góngora, Mario. 1987. Civilización de masas y esperanza y otros ensayos, Vicaría, Santiago de Chile, 1987, p. 15.

Revista de Historia, año 17, vol. 17(2), 2007, pp. 19-28
} 
Jaime Eyzaguirre, como muchos jóvenes de su generación, tenía una amplia inquietud intelectual y política en el campo de los movimientos social-cristianos. Formó parte de una agrupación llamada la Liga Social, cuyo órgano expresión, Falange ", dirigía. Esta pequeña publicación prestaba una gran atención a los sucesos políticos y culturales que a comienzos de la década de los treinta del siglo pasado tenían lugar en una aciaga Europa ${ }^{12}$. Con ocasión de la publicación de la obra de Ramiro de Maeztu Defensa de la Hispanidad, Jaime Eyzaguirre encargaría a uno de sus colaboradores (Antonio Cifuentes) una breve reseña de la misma; en ella se describía la obra del insigne intelectual español como un

"libro de amor y de combate. De amor a España eterna cuya esencia pretende desentrañar y lo logra magníficamente. De combate contra lo que Maeztu titula la Anti-Patria, y que tanto en España como en América ha pretendido rechazar todo el rico acervo de la tradición española". La reseña termina afirmando: "Hay que restaurar la Hispanidad. Y esa es la obra de las nuevas generaciones. Contra los ideales de la Revolución hay que levantar la trilogía de Maeztu... Servicio, Jerarquía y Hermandad"'3.

Poco tiempo después, con ocasión de la edición chilena de la obra de Maeztu ${ }^{14}$, sería Góngora el encargado de realizar el comentario del libro en otra de las revistas dirigidas por Eyzaguirre, esta vez se trataba de la prestigiosa Estudios ${ }^{15}$, editada por el Centro de Estudios Religiosos de la Universidad Católica, e impulsada por Otto Hanisch, padre del historiador y jesuita Walter Hanisch. Góngora aprovechaba los sucesos que acaecían en la España peninsular para escribir :

Mientras la Madre Patria se desangra en la más dolorosa de las luchas, aparece entre nosotros Defensa de la Hispanidad, la obra que aborda de manera genial el problema de la filosofía de la historia de España y señala las perspectivas del futuro. Obra... que exalta los valores espirituales y la tradición nacional por los que su autor... ha sabido inundar su propia vida. Obra que es un himno a la raza... Obra, en fin, que es brújula orientadora de la juventud que busca... un instante de expansión a sus ideales $^{16}$.

Precisamente Mario Góngora participaría en Chile de un homenaje al escritor español, cuando allí llegaron las confusas noticias de su detención en el Madrid republicano. En aquel homenaje también participaron, entre otros, Manuel Antonio Garretón Walker, destacado dirigente de la Falange Nacional ${ }^{17}$, y Joaquín Pérez de Rada, encargado de negocios del gobierno de Burgos ${ }^{18}$. Otro homenaje de similares características se organizaba algunos años después, con ocasión de un viaje a Chile de la hermana de Ramiro de Maeztu. En aquella ocasión Garretón se refería a la obra de Maeztu como

un mensaje vivo... clarín de marcha para nuevas empresas; un llamado vigoroso a los pueblos hispánicos para echar a caminar por nuevas rutas, señaladas por su vocación histórica, por el sentido profundo de su vida, por las razones propias de su genio ${ }^{19}$. La obra de Maeztu se alzaba como el fundamento indiscutible sobre el que [habría] de construirse el edificio espiritual de la hispanidad ${ }^{20}$.

\footnotetext{
"Este bolctín de la Liga Social se publicaría entre octubre de 1933 y octubre de 1935, editando un total de diecisiete números. Sus directores fueron Tomás Allende, Jaime Eyzaguirre y Roberto Barahona.

${ }^{12}$ Véase nuestro trabajo. 2001. Chile: desde la Falange Nacional a la Democracia Cristiana, UNED, Madrid, pp. 47-53.

${ }^{13}$ Falange, $\mathrm{N}^{\circ}$. 5, Santiago de Chile, agosto de 1934, p. 5.

${ }^{14}$ Maeztu, Ramiro de. 1936. Defensa de la Hispanidad, Editorial San Francisco, Santiago de Chile, 312 pp [Incluye como apéndice un discurso del arzobispo Isidro Gomá, pronunciado en 1934 durante la celebración del Día de la Raza en el Teatro Colón, Buenos Aires].

${ }^{15}$ Revista editada entre septiembre de 1932 y enero-marzo de 1955. Se publicaron un total de 255 números. Sus directores fueron Otto Hanisch, Jaime Eyzaquirre y Hugo Montes.

${ }^{16} \mathrm{G}$ [Góngora]. Estudios, $\mathrm{N}^{\circ}$ 51, Santiago de Chile, febrero de 1937, p. 72.

${ }^{17}$ Agrupación política de reciente fundación que adscribía los principios demócrata-cristianos, aunque no estaba exenta de influencias de la Falange española.

${ }^{18}$ El Diario Ilustrado, Santiago de Chile, 6 de septiembre de 1936.

${ }^{19}$ Azul, No 5, Santiago de Chile, 1939.

${ }^{20}$ Lira, Osvaldo. "Sentido de la Hispanidad. Notas en torno a un libro", en Estudios, N 30, Santiago de Chile, mayo de 1934, p. 38.
} 
La hispanidad dejaba huella en una generación de jóvenes educados en el seno de la Acción Católica; pero sería en Jaime Eyzaguirre donde adoptaría una dimensión más combativa. El Hispanismo, lejos de ser un objeto de estudio, se revela en Eyzaguirre como un signo de identificación personal. En 1947 escribía:

[Soy] hispano. Y no hispanista, que es actitud del extraño que admira desde fuera rasgos de la cultura ibérica. Ser hispano para el chileno es signo de filiación, no postura servil o imitativa ${ }^{21}$.

La hispanidad era presentada como la más sublime plasmación de la obra de España, la Madre Patria a la que se le debía la devoción y el amor que todo hijo debe sentir por sus progenitores:

A través de los personajes y caracteres de la literatura clásica sentí a España en mi carne y en mi sangre. Supe que rebelarse contra esa tradición era como traicionar la propia esencia. Vi mis raíces hundidas en la profundidad de la raza, a España como integrante en mí mismo. Y la amé con toda su grandeza y miseria, con su contenido y misión histórica ${ }^{22}$.

\section{VISION DE LA AMERICA ESPAÑOLA EN EYZAGUIRRE}

Sin duda el pensamiento de Jaime Eyzaguirre en relación a la hispanidad está disperso a lo largo de toda su obra histórica, aunque tal vez sea en su breve ensayo Hispanoamérica del Dolor donde se manifieste de una manera más fervorosa. A este breve ensayo habría que sumarle, al menos, otros dos trabajos: Fisonomía histórica de Chile (1948) e Ideario y ruta de la emancipación chilena (1957). Precisamente sería en el primero de estos ensayos donde escribía, en una nota preliminar (no incluida en su primera edición) estas breves líneas:

Nos duele Chile, la Patria chica, nos duele Hispanoamérica, la Patria grande. Y callar parecería consentir en una muerte que rechazamos ${ }^{23}$.

Eyzaguirre se sumaba así a las tesis del argentino Manuel Ugarte, del peruano José Riva Agüero, de los mexicanos José Vasconcelos, Carlos Pereyra o Alfonso Junco, de los nicaragüenses Pedro Antonio Cuadra o Julio Ycaza Tigerino, y la de tantos otros intelectuales de aquel continente cuya relación se escaparía al objeto de estas breves notas sobre el autor chileno.

Para Jaime Eyzaguirre la historia de los países que componen el mundo hispanoamericano no puede hacerse sin tener en cuenta, o desconociendo, la conquista de América por parte de España:

Iniciar automáticamente la existencia de estos pueblos con el año 1810 y poner en voluntario olvido 300 años de vida social en que se forjaron las bases culturales de todo el continente, es dejar sin significación el curso de los hechos, esconder el punto de convergencia familiar de veinte naciones y entregar, como consecuencia, a las generaciones futuras, una visión incompleta y adulterada de la historia ${ }^{24}$.

En otro lugar de la misma obra afirmaría:

Si historia es la sucesión consciente y colectiva de los hechos humanos, la de Chile sería inútil arrancarla de una vaga y fragmentaria antecedencia aborigen, carente de movilidad creadora y vacía de sentido y horizontes. Chile se revela como cuerpo total y se introduce en el dinamismo de las naciones al través de verbo imperial de España. Por eso la primera y más de una páginas siguientes de su vida serán páginas españolas, con todas las modalidades propias que se quiera, pero sin velar en esencia la fisonomía originaria ${ }^{25}$.

Esta idea es una constante en su obra:

\footnotetext{
${ }^{21}$ Eyzaguirre, Jaime.1969 Hispanoamérica del dolor, Editorial Universitaria, Santiago de Chile, p. 19.

${ }^{22}$ El Diario Ilustrado, 2 de diciembre de 1957, p. 2

${ }^{23}$ Eyzaguirre. Jaime. Hispanoamérica del dolor, p. 9.

${ }^{24}$ Eyzaguirre. Jaime. Fisonomía histórica de Chile. 1948. Edición de 1994. Editorial Universitaria, Santiago de Chile, p. 9.

${ }^{25}$ Ibídem, p. 14.

Revista de Historia, año 17, vol. 17(2), 2007, pp. 19-28
} 
Chile se incorporaba a la historia en el momento en que el español pisa su territorio. Antes este último se hallaba habitado por diversos pueblos sin ligamen racial y cultural. Nada de coincidente existía entre el atacameño, el araucano y el fueguino. La conciencia de una Patria común jamás se anidó en sus mentes. Fue español el que ató la invertebrada geografía de Chile, le dio sentido de unidad al territorio e infundió en sus habitantes un alma colectiva. El español trajo consigo el idioma, religión, derecho, instituciones y forma de vida... ${ }^{26}$.

La obra de la España peninsular en América habría permitido transmitir esos valores, todo lo que de grande y de valioso había en Occidente se habría trasladado a un nuevo mundo:

España, hija de Roma, nieta de Grecia, fue el cordón umbilical que ató la Patria en germen con la vieja Europa pletórica de cultura. Por esa vía llegó la lengua castellana que allá cantara las gestas medievales y que aquí se alzó atónita ante el plural heroísmo de la guerra de Arauco. Por el mismo conducto alcanzó a estas latitudes el derecho, para marcar las fronteras del orden y la libertad, del poder y de la justicia, por igual cauce advino el cristianismo en afanoso anhelo de moderar las discrepancias, de sanar con amor las heridas de la lucha armada, de hacer de poderosos y débiles seres iguales en esencia, emparejados por el implacable rasero de la muerte y el objetivo juicio de Dios ${ }^{27}$.

La labor de España no sólo fue una obra civilizadora sino que, además, se revela, en Eyzaguirre, como una labor evangelizadora. De esta forma la obra de España en el Nuevo Mundo no sólo es el vínculo de ésta con la cultura occidental, sino que también es la plasmación de los principios del catolicismo. En la historia de Occidente la religión cristiana habría encontrado hasta ahora dos grandes y ricas expresiones: la cultura románico-gótica que abrazó toda Europa Occidental y la tridentino-barroca que por espacio de dos siglos rebasó ambas latitudes del mundo hispánico ${ }^{28}$. "La hispanidad -afirmaría Eyzaguirre- no es en la historia sino el imperio de la fe" ${ }^{29}$.

Hispanismo y catolicismo son para Eyzaguirre realidades inseparables. Esta conjunción la describe del siguiente modo:

La estratégica ubicación de la península ibérica que, conforme al bello decir de la griega Alexandra Evaris, es: "proa de Europa, puente hacia el Africa, eco de Asia, etapa de América"; la variada y multiforme serie de naciones que la han invadido y que con su policromía étnica han logrado aportar ricos matices al carácter español; en fin, la idiosincrasia personalista de este último, generadora de su elevado concepto de la dignidad humana, hacen de la raza española y de cada uno de sus miembros un tipo universal ${ }^{30}$.

Pero, tras la gestación de las diferentes naciones que nacieron de esa inmensa labor realizada por la España imperial vino el momento de la emancipación. En este punto, interesante se muestra la visión de Eyzaguirre sobre ese proceso de ruptura de los diferentes territorios de la América hispana con la Madre Patria. En un primer momento Eyzaguirre comienza por recordarnos que más que la independencia se buscaba una mayor autonomía respecto de la metrópoli. Refiriéndose al caso concreto de Chile ponía de manifiesto cómo aquel cabildo abierto del 18 de septiembre de 1810 no representaba la separación definitiva de la corona española, ya que se hizo en nombre del Rey de las Españas. Pese a ello, reconocía que aquel cabildo constituyó el primer paso de un largo proceso que llevaría a la independencia de Chile dieciocho años después ${ }^{31}$.

En este sentido hay quien ha querido ver detrás de sus tesis la mano del español Manuel Giménez Fernández y su libro Las doctrinas populistas en la independencia de América ${ }^{32}$. Según este autor la independencia encontraría sus raíces en la tradición española, y particularmente el concepto de que las colonias dependían del rey y no de España. Desde esta base se podría justificar que tras la invasión de las tropas napo-

${ }^{26}$ Eyzaguirre, Jaime. 1966. Historia de las Instituciones políticas y sociales de Chile, Editorial Universitaria, Santiago de Chile, p. 19.

${ }^{27}$ Eyzaguirre, Jaime. Hispanoamérica del dolor, p. 17.

${ }^{28}$ Krebs, Ricardo. "Algunos aspectos de la visión histórica de Jaime Eyzaguirre", en Historia, No 7, Santiago de Chile, p. 17.

${ }^{20}$ Eyzaguirre, Jaime. Chile en el tiempo. Sangre y dolor de España, Editorial Nueva Universidad, Santiago de Chile, s/f, p. 54.

${ }^{30} \mathrm{Ibid}$.

"Eyzaguirre, Jaime. Historia de las Instituciones Politicas y Sociales de Chile, Editorial Universitaria, Santiago de Chile, 1989, pp. 60-63.

${ }^{32}$ Primera Edición: Escuela de Estudios Hispanoamericanos, Sevilla, 1947. 
leónicas en la península ibérica los territorios tendrían el derecho a autogobernarse por sí mismos. Para Jaime Eyzaguirre el proceso emancipador derivaría, por lo tanto, de la tradición de los fueros municipales y de la reversión de la soberanía al pueblo en ausencia del soberano; la emancipación se mostraría así como una muestra más de la fecundidad y fortaleza de la tradición hispana:

Cuando el monarca, símbolo exterior de la unidad, desaparece con la invasión napoleónica, las fuerzas de la dispersión regionalista representada por los cabildos, antes cohibidas y superadas, ven ahora rotas todas las trabas que detenían su poder. El sentido de cohesión unilateral universal desaparece para siempre y el particularismo se enraíza con tal violencia que ya no será posible recomponer en un todo los fragmentos del antiguo imperio español, día a día más divergentes... Aquí es donde puede apreciarse con más fuerza el absurdo de los que pretenden colocar en el mismo plano el movimiento de emancipación de las colonias anglosajonas y el de las provincias hispanoamericanas. No hay afinidad en los antecedentes históricos ni en la postura vital de los héroes de ambas revoluciones. Es increíble hasta donde, en hechos y hombres de apariencias similares, supo cada raza mantener su sello inconfundible y marcar el abismo de la diferencia ${ }^{33}$.

Eyzaguirre une aquí su análisis de la historia con su catolicismo militante, del que nos ocuparemos más adelante, y encuentra en la escolástica y su teoría del poder un claro antecedente de las causas últimas del movimiento emancipador ${ }^{34}$. En este sentido el autor chileno escribe:

El movimiento juntista fue activado por la circulación de diversos pasquines de propaganda, entre los que sobresalió el "Catecismo Político Cristiano" firmado con el pseudónimo José Amor de la Patria, atribuido sin más fundamento a Martínez de Roza. El autor anónimo del Catecismo actualizó la tradicional doctrina española del origen inmediato del poder en el pueblo, advirtiendo que ella ha sido la doctrina sensata de los santos, de los filósofos y de los sabios de la antigüedad pero los reyes la han hecho proscribir de las tierras de su imperio ${ }^{35}$.

Eyzaguire también prestó atención a otra obra de similares características, el Diálogo de los Porteros ${ }^{36}$. A su parecer en ambos panfletos se puede rastrear el pensamiento político y filosófico de los tratadistas españoles del Siglo de Oro como Suárez y Victoria.

Esta tesis se opondría a aquellas otras, como la defendida por historiadores abiertamente marxistas, como el caso de Hernán Ramírez Necochea, que pretenden presentar, en la más pura ortodoxia del materialismo histórico, el proceso de "independencia" como una expresión particular de la transición de un régimen feudal al capitalismo ${ }^{37}$.

Para concluir este breve apartado también añadiremos que Eyzaguirre minimizaba la influencia que sobre el proceso emancipador pudieran haber ejercido otras potencias extranjeras, principalmente Inglaterra:

De la manera que España había ayudado a quebrantar la potencia británica en el Nuevo Mundo, favoreciendo la emancipación de los Estados Unidos, Inglaterra estaba empeñada en romper la hegemonía española en América. Hubo proyectos que quedaron en papel, como el del Vizconde Melvilla, en 1798, para equipar una expedición de conquista de Chile... también, se llevaron a cabo fuertes ataques armados a Cartagena de Indias en 1740, a Cuba en 1762, a Buenos Aires en 1806. En ninguno de ellos el invasor inglés pudo, empero, capitalizar en beneficio propio el resentimiento de los criollos hacia los peninsulares y romper la fidelidad de los primeros a la corona castellana ${ }^{38}$.

\footnotetext{
${ }^{33}$ Eyzaguirre, Hispanoamérica del dolor, p. 32.

${ }^{34}$ Sobre este tema véase el trabajo de Maria Saavedra Inaraja. "Escolástica e Ilustración en el pensamiento de la emancipación Hispanoamericana. Consideraciones en torno a algunos de sus textos", en Aportes, $\mathrm{N}^{\circ}$ 55, Madrid, 2/2004, pp. 21-34.

${ }^{35}$ Eyzaguirre, Historia de las Instituciones Politicas y Sociales de Chile, p, 61.

${ }^{36}$ Obra de Manuel de Salas y Corbalán. Fue uno de los más ardorosos promotores de la instalación de la Primera Junta de Gobierno (1810); durante la llamada Patria Vieja desempeñó varios cargos políticos: diputado por Itata en el primer Congreso Nacional (1811); secretario de Relaciones Exteriores (1812) y miembro del Senado Consultivo (1814). Además, intervino en la promulgación del Reglamento Constitucional chileno de 1812, participando activamente en la redacción de la Aurora de Chile, el pasquín que dirigiera Camilo Henríquez González. Fue un claro exponente del pensamiento ilustrado en Chile.

${ }^{37}$ Ramírez Necochea, Hernán. 1967. Antecedentes económicos de la Independencia de Chile, Editorial Universitaria, Santiago de Chile.

${ }^{38}$ Eyzaguirre, Jaime. 1965. Historia de Chile, Editorial Zig-Zag, Santiago de Chile, pp. 348-349.
}

Revista de Historia, año 17, vol. 17(2), 2007, pp. 19-28 


\section{HISPANIDAD COMO ARMA DE COMBATE}

La política continental del momento (años 30 y 40 del siglo XX) se movía entre aguas turbulentas: el "panamericanismo", detrás del cual se encontraría la política imperial de los Estados Unidos; el "indigenismo", sustentado por la izquierda populista seguidora de las tesis de Raúl Haya de la Torre, y el "latinoamericanismo", un vago intento de desconocer la obra de España en América. Desde un punto de vista historiográfico Jaime Eyzaguirre afirmaría:

"Si el término Indoamérica sustituye el factor común cristiano y occidental de nuestra cultura por una deificación racista que se repliega ciegamente en los bajos estratos de la biología para rechazar todo contacto con el espíritu universal, la otra denominación de Latinoamérica, aunque más inofensiva y menos falsa, disfraza malamente el propósito de diluir el nombre español en una fórmula genérica, que dará cabida preponderante a otras naciones, muy ilustres sin duda, pero que no estuvieron presentes en las etapas culminantes de la conquista y colonización" ${ }^{39}$. Frente a estas tesis lo que cabía hacer era "abandonar los caminos mercenarios [clara alusión al panamericanismo] y actualizar... los valores eternos que alimentaron en América el único esbozo de verdadera y genuina cultura continental. Y esa es la tarea básica de la nueva generación católica, obligada a infundir en las relaciones sociales, por encima de los prejuicios políticos, de razas y de clases, un hálito de honda justicia y de viviente caridad"40.

A principios de los años 30 Jaime Eyzaguirre, como otros jóvenes social-cristianos, formaría parte de la Asociación Hispano-Chilena de Cultura, que funcionó como una tertulia en los locales de la Asociación Nacional de Estudiantes Católicos; pero el estallido de la Guerra Civil española y la postura favorable al bando nacional del grupo de la revista Estudios, encabezado por Jaime Eyzaguirre, y el neutralismo de la Falange Nacional, grupo político liderado por Manuel Antonio Garretón y Eduardo Frei (seguidores -estos últimos- de las tesis de Jacques Maritain sobre el conflicto), determinarían la disolución de este incipiente intento de agrupar las diferentes posiciones hispanistas ${ }^{41}$.

Algún tiempo después, en mayo de 1940, se daba a conocer en la prensa local la creación del Instituto Hispano-Chileno de Cooperación Cultural. Se creía necesario afianzar los lazos de la lengua y la cultura con España más allá de los asuntos relativos a la política contingente. La nueva asociación estaba presidida por el jurista y destacado líder conservador, Pedro Lira Urquieta, aunque detrás del grupo estaban los esfuerzos de Jaime Eyzaguire, Roque Esteban Scarpa y el escritor español José María Souvirón ${ }^{42}$. Los miembros de la Falange Nacional chilena también se sumaron a esta nueva iniciativa de tender puentes de unión cultural entre Chile y España. Desde luego la presencia en Chile de Torcuato Luca de Tena, embajador de España, aportó un apoyo esencial a esta nueva experiencia.

Este Instituto tampoco tendría una larga vida, pero se adelantó a la creación del Instituto de Cultura Hispánica, fundado el 11 de noviembre de 1947, que contó con 29 filiales a lo largo de todo el mundo, incluidos los países de lengua portuguesa o las Islas Filipinas. La sede chilena, inaugurada el 25 de julio de 1948, fiesta de Santiago Apóstol, sería presidida por Pedro Lira, junto a él se encontraban Souvirón y Jaime Eyzaguirre. Este último acababa de regresar de España, donde había permanecido por un espacio de 7 meses, invitado por el gobierno español para impartir diversas conferencias (algunas en la Cátedra Ramiro de Maeztu ${ }^{43}$ ); su estancia en la península ibérica también le permitió, además, entrar en contacto con numerosos intelectuales y autoridades políticas ${ }^{44}$.

\section{HISTORIA Y CATOLICISMO}

No se podría concluir un trabajo sobre el insigne historiador chileno sin hacer referencia a su fe como ele-

${ }^{39}$ Eyzaguirre, Jaime. Hispanoamérica del dolor, p. 30.

${ }^{40}$ Eyzaguirre, Jaime. 1939 "Prolegómenos a una Cultura Hispanoamericana", en Estudios, №. 18, Santiago de Chile, mayo.

${ }^{41}$ Díaz Nieva, José y Cristián Garay Vera. 2002. "Los católicos chilenos y la Guerra Civil española", en Alfonso Bullón de Mendoza y Luis Togores: Revisión de la Guerra Civil española, Actas, Madrid, pp. 1035-1050.

${ }^{42}$ Souvirón permanecería en Chile desde 1941 hasta 1953. Fue catedrático de Literatura en la Universidad Católica de Chile. y director de la Editorial Zig-Zag.

${ }^{43}$ Día 18 de febrero: "La fisonomía caballeresca de la conquista indiana", día 20 de febrero. "El sentido ético-jurídico de la colonización en Chile" y día 24 de febrero: "El aporte vasco a la nacionalidad chilena".

${ }^{44}$ Sobre el tema ver trabajo inédito de Cristián Garay Vera: La recepción del Hispanismo: Maeztu, el franquismo y Chile. 1931-1948. 
mento determinante en su pensamiento. Como se recordará, Jaime Eyzaguirre cursó sus estudios de enseñanza primaria y secundaria en el Liceo Alemán. El joven estudiante participaba, como otros muchos de sus correligionarios, de las diferentes actividades que en el liceo se realizaban, entre ellas una pequeña academia literaria, que también editaba una memoria anual. Sería en este anuario donde Jaime Eyzaguire publicaría en 1924, a los 16 años de edad, su primer trabajo, titulado "El cristianismo y la civilización". En él intentaba plasmar la idea de que la historia del mundo civilizado y la historia del cristianismo se identifican de tal forma que hablar de una implicaría hacer referencia a la otra. Desde este momento Eyzaguirre, ya sea como historiador, en el campo político, o simplemente como hombre, destacaría, ante todo, como un católico militante. Desde esta premisa habría que reparar en su concepción de la historia. Para ello es necesario detenernos en la influencia que sobre él ejerció el sacerdote Juan Salas, el cura párroco de la Iglesia de San Juan Evangelista, quien revitalizara las doctrinas del sacerdote Miguel Lacunza ${ }^{45}$ y el milenarismo. Como se recordará, el milenarismo, tras interpretar algunos pasajes de las Sagradas Escrituras (por ejemplo, el Capítulo 20 del Apocalipsis), sostiene que entre la derrota del Anticristo y el juicio final universal habrá un largo espacio de tiempo en el cual se establecería en la tierra un reino de los Santos con Cristo ${ }^{46}$.

Habría que puntualizar que el milenarismo no habría sido del agrado de la jerarquía eclesiástica chilena, quien en 1940, a instancias de los obispos Manuel Larraín y Alejandro Hunneus, lo habría condenado. Esta primera condena fue contestada por Eyzaguirre desde las páginas de la revista Estudios:

Se dice que aunque el milenarismo no es en sí una herejía, el profesarlo produce en sus adeptos quietismo esterilizador, espíritu de rebelión contra la jerarquía y culto protestante de la Escritura con desprecio de la tradición. Apenas puedo comprender cómo pueden derivarse resultados tan lamentables de una doctrina que, en la negra realidad histórica en que vivimos, trae sano impulso de acción y pone luz de optimismo con la esperanza del triunfo definitivo de Cristo en su gloriosa venida; de una doctrina que al decir de su más ilustre impugnador, San Jerónimo, ha dado muchos santos y mártires ${ }^{47}$.

Pese a todo, Jaime Eyzaguirre acoge con respeto y sumisión esta condena, más aún después de pronunciarse el Santo Oficio sobre el tema en 1944, prohibiendo propagar su doctrina, por que consideraba que no podía enseñarse con total seguridad. No obstante, el milenarismo continuará estando presente en el pensamiento de Eyzaguirre, quien creía firmemente en la posibilidad efectiva de ver realizado el reino de Cristo, no en un cielo etéreo, con mengua y destrucción de la materia, sino aquí en la propia tierra, como una obra salida de la mano de Dios. En una entrevista realizada a pocos años de su muerte hablaba de su visión de los grandes períodos de la historia y de su relación con la obra redentora de la humanidad:

La Historia es la realización de la idea de Dios en el plano del hombre a través de su libertad. En la Historia hay dos grandes ciclos o períodos: la manifestación de la unidad de Dios a través del pueblo judío y su monoteísmo; y la manifestación de la unidad por medio de la Iglesia. La primera etapa representaba la antigua alianza, celebrada entre Dios y el pueblo elegido. En este pueblo nacerá el Mesías, el salvador de la humanidad. El segundo ciclo histórico se inició con la fundación de la Iglesia. En ella, Dios Uno se abre como una esfera y se muestra en su triple aspecto, en sus tres personas, cada una de las cuales se proyecta en la Historia. Consecuentemente, en este segundo ciclo es posible distinguir tres personas: 1) El Reino del Espíritu Santo que se inicia en Pentecostés y termina con la Parusía; 2) el Reino de Cristo que se manifiesta en la segunda venida o Parusía y 3) el Reino eterno del Padre ${ }^{48}$.

En el campo político a Jaime Eyzaguirre se le ha considerado por cierta corriente historiográfica como un pensador conservador ${ }^{49}$, aunque de hecho está muy lejos de ser concebido como tal. Sus lecturas juveniles de los españoles Juan Donoso Cortés, Jaime Balmes o Juan Vázquez de Mella, las de un Nicolás Berdiaeff, o,

\footnotetext{
${ }^{45}$ Miguel Lacunza (1731-1801). Ingresó a los dieciséis años a la Compañía de Jesús, ordenándose sacerdote en 1755 a la edad de veinticuatro años; es autor de una obra que lleva por título Venida del Mesias en gloria y majestad.

${ }^{46} \mathrm{La}$ obra de Lacunza descansó sobre tres postulados básicos. Primero, la apostasía de la iglesia cristiana. Segundo, la conversión del pueblo de Israel y restauración de su alianza con Dios. Tercero, le venida por segunda vez del Mesías en gloria y majestad, a la cabeza de los santos resucitados, del pueblo de Israel y los gentiles que no hayan apostatado, derrotará a sus enemigos y reinará por mil años en Jerusalén antes del fin de los tiempos y el Juicio Final.

${ }^{47}$ Eyzaguirre, Jaime. 1940. "La Iglesia Patrística y el Milenarismo", en Estudios, № 10, Santiago de Chile, junio, p. 69.

${ }^{18}$ El Diario Ilustrado, Santiago de Chile, 2 de diciembre de 1956, p. 2.

${ }^{49}$ Cristo, Renato y Carlos Ruiz. 1992. El pensamiento conservador en Chile, Editorial Universitaria, Santiago de Chile.
}

Revista de Historia, año 17, vol. 17(2), 2007, pp. 19-28 
incluso, las del primer Jacques Maritain, le situarían en el campo del Tradicionalismo político, junto con otros ilustres chilenos como el padre Osvaldo Lira, el también historiador Mario Góngora, o su cuñado, el jurista Julio Philippi. Ellos constituían el alma de la revista Estudios. Pero veamos cómo definía Eyzaguirre la "Tradición":

Tradición es hablar la propia voz, es marcar la vida con el sello vernáculo, es escribir las mil palabras con la pluma propia, firme e inconfundible. Tradición es algo que trasciende a la mutación incesante del tiempo, es vida, es germen activador, siempre fecundo, nunca agotado. Es tradición todo aquello que ha llegado a incorporarse a los pueblos como algo inherente a su propia persona, y de la cual no podrían ellos prescindir sin poner en peligro su existencia misma. Es tradición la columna vertebral que cohesiona este ejército en marcha que es la Patria o la comunidad cultural, integrado por los seres hoy vivos, por los que ya son sombras venerables y pasadas, y por los que vendrán en el futuro esperado. Tradición es aquello que sin perder su inmutabilidad intrínseca presenta en el curso de la historia manifestaciones de diversidad analógica. Tradición es el motivo de su existencia, es la razón de ser, la voluntad de vida, en fin, la forma sustancial de un pueblo, como es su materia prima el medio geográfico, la raza y el idioma ${ }^{50}$.

Finalmente, y para terminar, no faltaba quien tachase a Jaime Eyzaguirre de integrista e intolerante, tanto en el campo de lo religioso como en el político, e incluso en el intelectual. Eyzaguirre, lejos de tratar de excusarse, o de escabullir tales acusaciones, proclamaba sin ningún tipo de rubor:

Yo no soy tolerante, porque es estúpido creer que la verdad y el error tienen iguales derechos. Pero mi intolerancia no se trata de una agresividad hacia el adversario. La intransigencia con el error, no sólo es incompatible, sino que obliga al amor hacia la persona equivocada. ¿Cuántas almas habilísimas están llenas de buena fe en una postura errada? ¿Cómo darles a ellos la verdad, si levantamos frente a las mismas una muralla de rencores y prejuicios? ${ }^{51}$.

\section{HERENCIA DE JAIME EYZAGUIRRE}

Es difícil plasmar en unas breves líneas la herencia intelectual de Jaime Eyzagurre; tal vez habría que comenzar por aquellas instituciones tras las cuales la huella de Eyzaguirre aún está presente. En este sentido habría que referirse a la Academia Chilena de la Historia (cuya sede actual se encuentra en la que fue la casa de Sergio Fernández Larraín ${ }^{52}$, quien desempeñó el cargo de embajador en España 1958-1963); dicha institución fue fundada en enero de 1933 a instancia de varios de los miembros de la Sociedad Chilena de Historia y Geografía. Jaime Eyzaguirre ocuparía el cargo de secretario general, de forma ininterrumpida, entre 1935 hasta la fecha de su muerte. De su magna obra, que suma un total de 347 trabajos, una gran parte (un total de 40 artículos) fue publicada en el Boletín de la Academia Chilena de la Historia.

En 1954, en el seno de la Universidad Católica, Jaime Eyzaguirre fundó el Instituto de Investigaciones Históricas. No puede decirse que este Instituto tuviera en sus inicios una vida intensa, salvo la publicación de algunas monografías y la realización de algunos seminarios; pero de todas esas actividades habría que reparar en la edición de lo que sería su anuario, un boletín llamado simplemente Historia, cuyo primer número saldría publicado en el año 1961. Pese a ser concebido como un anuario, su publicación no siempre cumplió esa periodicidad, de hecho su segundo número estaba en prensa al momento del fallecimiento de Eyzaguirre. Después de su muerte se ha venido publicando de forma regular hasta el día de hoy, constituyendo un apartado esencial su "Fichero Bibliográfico"; esta sección, dirigida en la actualidad por Juan Ricardo Couyoumdjian, recoge las novedades que sobre la historia de Chile y de América aparecen publicadas en el último año.

Jaime Eyzaguirre dejó también una amplia escuela: Gonzalo Vial, Antonio Dougnac, Fernando Silva, José Armando de Ramón, Ricardo Krebs, Horacio Aránguiz, Cristián Zegers, Esteban Scarpa, Patricio Estellé, son sólo una muestra. También cabría referirse a los "discípulos" indirectos, aquellos que nunca acudieron a sus

\footnotetext{
${ }^{{ }^{50}}$ Eyzaguirre, Jaime. Hispanoamérica del dolor, pp. 40-41.

${ }^{51}$ El Diario Ilustrado, Santiago de Chile, 2 de diciembre de 1956, p. 2.

${ }^{52}$ Sobre este personaje de la historia chilena véase el trabajo de Sergio Salas Fernández. 2006. "Sergio Fernández Larraín (1909-1983). Una Inquieta existencia", en Boletín de la Academia Chilena de la Historia, No 115, Santiago de Chile, pp. 245-289.
} 
clases, y que pese a ello han mantenido viva la llama del maestro; aquellos que comparten con aquél una misma visión histórica de América; entre estos podemos citar a Bernardino Bravo Lira, René Millar o Cristián Garay Vera: tres generaciones de historiadores unidos por esa cosmovisión de la historia de América desde la hispanidad. Sus trabajos sobre historia de las instituciones, la inquisición o el pensamiento tradicionalista español son sin duda un referente de obligada consulta para quien pretenda acercarse a esos temas.

\section{BIBLIOGRAFIA}

Barros Arana, Diego. 1884-1902. Historia General de Chile, publicada en 16 volúmenes.

Bravo Lira. Bernardino. 1995. "Jaime Eyzaguirre, historiografía chilena y conciencia nacional en el siglo XX", en Hanisch Espíndola, Walter et al.1995. Jaime Eyzaguirre. Historia y Pensamiento, Editorial Universitaria, Universidad Alonso Ovalle, Santiago de Chile.

Castedo, Leopoldo y Francisco A. Encina A.1954. Resumen de la Historia de Chile. En 1982 agregó L. Castedo un cuarto volumen.

Díaz Nieva, José. 2001. Chile: desde la Falange Nacional a la Democracia Cristiana, UNED, Madrid. Encina Armanet, Francisco Antonio. 1940-1952. Historia de Chile, desde la prehistoria hasta 1891, Santiago de Chile (20 vols).

Eyzaguirre, Jaime. s/f Chile en el tiempo. Sangre y dolor de España, Editorial Nueva Universidad, Santiago de Chile.

Eyzaguirre, Jaime. 1933. "Generaciones y Semblanzas. Los Antepasados de Don Agustín de Eyzaguirre". Boletín de la Academia Chilena de la Historia, № 9, Santiago de Chile, pp. 155-276.

Eyzaguirre, Jaime. 1939. "Prolegómenos a una Cultura Hispanoamericana", en Estudios, N 18, Santiago de Chile, mayo.

Eyzaguirre, Jaime. 1940. "La Iglesia Patrística y el Milenarismo", en Estudios, No 10, Santiago de Chile.

Eyzaguirre, Jaime. 1965. Historia de Chile, Editorial Zig-Zag, Santiago de Chile.

Eyzaguirre, Jaime. 1968. El alcalde del año diez. Editorial Andrés Bello, Santiago de Chile.

Eyzaguirre, Jaime. 1966. Historia de las instituciones políticas y sociales de Chile, Editorial Universitaria, Santiago de Chile.

Eyzaguirre, Jaime. 1973. Historia de Chile. Génesis de la nacionalidad (2 ${ }^{\mathrm{a}}$ Edición), Zig-Zag, Santiago de Chile.

Eyzaguirre. Jaime. (1948) 1994. Fisonomía histórica de Chile. Editorial Universitaria, Santiago de Chile.

Figueroa, Virgilio. 1925-1931. Diccionario Biográfico y Bibliográfico de Chile, Impr. y Litogr. La Ilustración, Santiago de Chile, tomo III, pp. 110-115.

Góngora, Mario. 1987. Civilización de masas y esperanza y otros ensayos, Vicaría, Santiago de Chile.

Góngora, Alvaro; Alexandrine de la Taille y Gonzalo Vial. 2002. Jaime Eyzaguirre en su tiempo, Universidad Finis Terrae, Editorial Zig-Zag, Santiago de Chile.

Krebs, Ricardo. "Algunos aspectos de la visión histórica de Jaime Eyzaguirre", en Historia, № 7, santiago de Chile, p. 17.

Lira, Osvaldo. 1934. "Sentido de la Hispanidad. Notas en torno a un libro", en Estudios, N 30, Santiago de Chile, mayo.

Maeztu, Ramiro de. 1936. Defensa de la Hispanidad, Editorial San Francisco, Santiago de Chile.

Ramírez Necochea, Hernán. 1967. Antecedentes económicos de la Independencia de Chile, Editorial Universitaria, Santiago de Chile.

Vicuña Mackenna, Benjamín (1831-1886). Político e historiador. Su principal obra fue Historia General de la República de Chile. Desde la Independencia a nuestros días, 1866-1882 (5 vols). 